hydrochloric acid (blank) and the excess of the acid after absorption of the ammonia.

The proposed modification may be of use in many other analytical procedures involving the use of the Conway microdiffusion method.

\section{SUMMARY}

The ordinary Conway Unit has been modified by the addition of a peripheral chamber, to be filled with the same liquid as the outer diffusion chamber (except for the fluid to be analysed). An inverted Petri dish dipped into this chamber forms a liquid trap.

\section{REFERENCES}

Conway, E. J. (1950). Microdiffusion Analysis and Volumetric Error, 3rd ed. London: Crosby Lockwood and Son. Gordon, H. T. (1952). Analyt. Chem. 24, 857.

Kinsey, V. E. \& Robison, P. (1946). J. biol. Chem. 162, 325.

Pirt, S. J. \& Chain, E. B. (1952). Biochem. J. 50, 716.

\title{
The Isolation of 16-epiOestriol from the Urine of Pregnant Women
}

\author{
BY G. F. MARRIAN AND W. S. BAULD \\ The Department of Biochemistry, University of Edinburgh
}

\section{(Received 17 August 1954)}

Many of those who have employed fluorescence reactions with sulphuric or phosphoric acids for the quantitative determination of the oestrogens have noted that phenolic fractions obtained from acidhydrolysed human urine contain fluorogens other than oestriol (oestra-1:3:5-triene-3:16 $\alpha: 17 \beta$-triol), oestrone or oestradiol-17 $\beta$ (cf. Engel, 1950; Zondek \& Finkelstein, 1952). While hitherto there has been no evidence to indicate that this 'non-specific' fluorescence is due to substances chemically related to the oestrogens, recent work suggests that it is in part due to substances closely resembling the oestrogens in their solubilities. Thus Migeon (1953), using countercurrent distribution methods, detected three unknown fluorogens in extracts from the urines of normal men and women and patients with hyperactivity of the adrenal cortex, and he showed that these had partition ratios intermediate between those of oestriol and oestradiol-17 $\beta$ in one of the solvent systems employed. More recently Braunsberg, Stern \& Swyer (1954) have reported that all samples of crystalline oestriol examined by them contained a fluorogenic impurity which was eluted slightly in front of oestriol itself from partition chromatographic columns in which an alkaline aqueous stationary phase was employed.

Convincing evidence indicating the presence of a substance in human urine, chemically related to, but not identical with oestriol, oestrone or oestradiol-17 $\beta$, has been obtained using the highly specific Kober reaction (as modified by Brown (1952) and by Bauld (1954)). Our colleague Dr J. B. Brown (personal communication) has detected the presence of a fourth Kober-chromogen in acidhydrolysed human pregnancy urine by experiments involving chromatography on alumina columns of methylated phenolic fractions. This fourth Koberchromogen was found by him to be eluted less readily than the 3-methyl ether of oestradiol-17 $\beta$, but more readily than the 3-methyl ether of oestriol. Working independently, one of us (W.S.B.) detected a fourth Kober-chromogen in the oestriol fraction obtained from the urine of a non-pregnant woman. This unknown chromogen was eluted from partition chromatographic columns somewhat in front of oestriol using the system $70 \%(\mathrm{v} / \mathrm{v})$ aqueous methanol-ethylene dichloride.

The evidence indicating the presence of a fourth Kober-chromogen (KC-4) in human urine appeared to be so convincing that it was decided to attempt its isolation and identification.

\section{RESULTS}

\section{Isolation of $\mathrm{KC}-4$}

In the first instance several small batches of pooled pregnancy urine were worked up in order to develop methods for the concentration of KC-4 which could be conveniently used in subsequent largescale experiments. For the detection of $\mathrm{KC}-4$ in these trial fractionations column partition chromatograms, using the system $70 \%$ methanol on Celite-ethylene dichloride (Bauld, 1953), were employed.

Oestriol fractions containing KC-4 were prepared from ether extracts of the acid-hydrolysed urine both by the usual benzene-water partition procedure and by the original procedure of Cohen \& Marrian (1934) involving extraction of a 'strong phenolic' fraction by $0.1 \mathrm{~N}-\mathrm{NaOH}$ from ether. The latter procedure, being more economical in solvents, was clearly preferable for large-scale use. 
Treatment of such oestriol fractions with cold ethyl acetate removed most of the brown gummy material, leaving a sparingly soluble solid crystalline residue of crude oestriol (Marrian, 1930). This contained KC-4, while little of the latter was found to be present in the ethyl acetate soluble gum. Further concentration of the KC-4 without much loss was achieved by removing part of the oestriol from the crude solid by crystallization from methanol. It may be of interest to note that oestriol recrystallized twice from methanol was free from KC-4 as far as could be determined by the methods employed.

Concentrates prepared in this way still contained, however, about 40 times as much oestriol as KC-4, assuming that the two compounds were equally chromogenic in the Kober reaction; and accordingly it was clear that without further concentration it would not be practicable to use partition chromatogram columns for the large-scale separation of KC-4 from the oestriol, owing to the very low solubility of the latter in nearly all solvents.

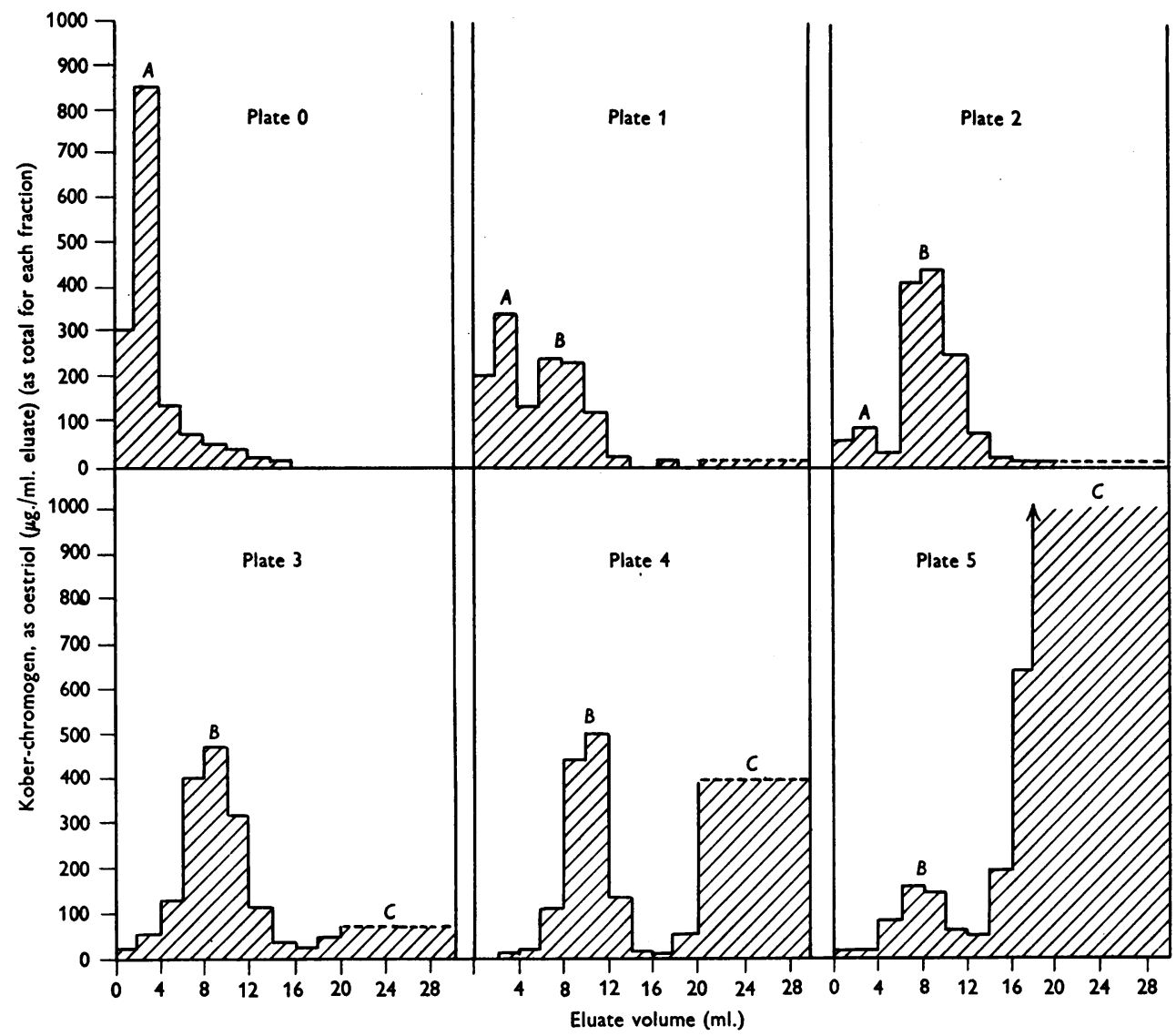

Fig. 1. Analytical column partition chromatograms (70\% methanol-ethylene dichloride) on fractions separated from KC-4 concentrate by 8-transfer countercurrent distribution between ether (stationary phase) and $\mathrm{pH} 12 \cdot 0$ buffer (mobile phase). (Plates 0-5 only are shown.) $A$, 'less polar' Kober-chromogen; $B$, KC-4; $C$, oestriol.
In an attempt to achieve further separation of KC-4 from oestriol, countercurrent distribution of the mixture between ether and aqueous alkaline buffer solutions was investigated. It was found that by an eight-transfer operation in separating funnels with a phosphate buffer at $\mathrm{pH} 12.0$ a considerable degree of separation of $\mathrm{KC}-4$ from oestriol could be achieved, the latter behaving in the system as the more 'polar' substance. Furthermore, a good separation of KC-4 from a less 'polar' Kober-chromogen was also achieved. The latter substance was subsequently found to be ketonic, and it seems possible that it was oestrone which had 'leaked' into the oestriol fraction in small amounts. The results obtained by carrying out analytical partition chromatograms on the fractions obtained from the first six 'plates' in the countercurrent separation are shown in Fig. 1.

Although the countercurrent procedure yielded a KC-4-rich fraction from which over $90 \%$ of the oestriol originally present had been removed, it still contained too much of the latter to permit of the 
ready preparation of pure KC.4 by direct crystallization. However, owing to the considerable reduction in bulk effected by this procedure it was thought that it might be practicable, even on a large scale, to complete the separation on a partition chromatogram column. This was indeed found to be possible; and when the above-described purification procedures were applied to the 'strong phenolic' fraction from 210 l. of pooled pregnancy urine a KC-4 fraction free from oestriol was obtained (see Fig. 2) which eventually yielded $10.3 \mathrm{mg}$. of a crystalline product melting at $277-280^{\circ}$ and having $[\alpha]_{\mathrm{D}}^{19}+85^{\circ}$ (in ethanol).

\section{Identification of $\mathrm{KC}-\mathbf{4}$}

The product gave $\mathbf{C}$ and $\mathbf{H}$ analyses in good agreement with those required for a substance of the formula $\mathrm{C}_{18} \mathrm{H}_{24} \mathrm{O}_{3}$, and on acetylation it yielded a triacetate, m.p. 151-152 ${ }^{\circ}$. The ultraviolet absorption spectrum in ethanol $\left(\epsilon_{281}, 2165\right)$ was virtually identical with that of authentic oestriol $\left(\epsilon_{281}, 2181\right.$; see Fig. 3). The melting points of KC-4 and of its

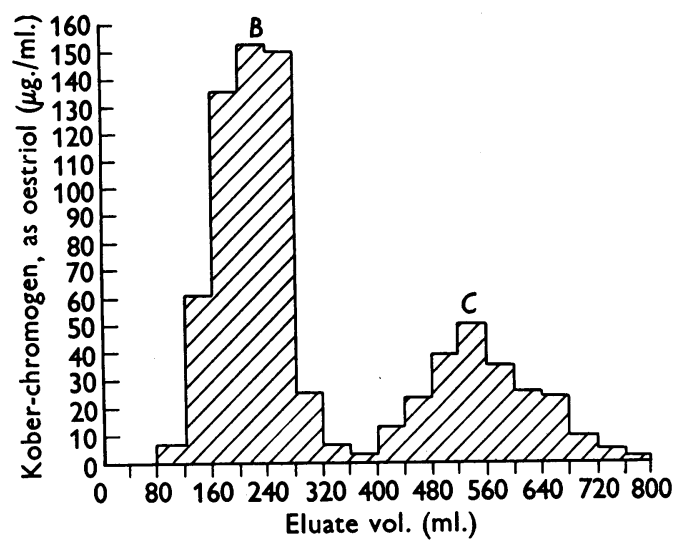

Fig. 2. Preparative column partition chromatogram (70\% methanol-ethylene dichloride) on KC-4 enriched oestriol fraction. $B$, KC-4; $C$, oestriol.

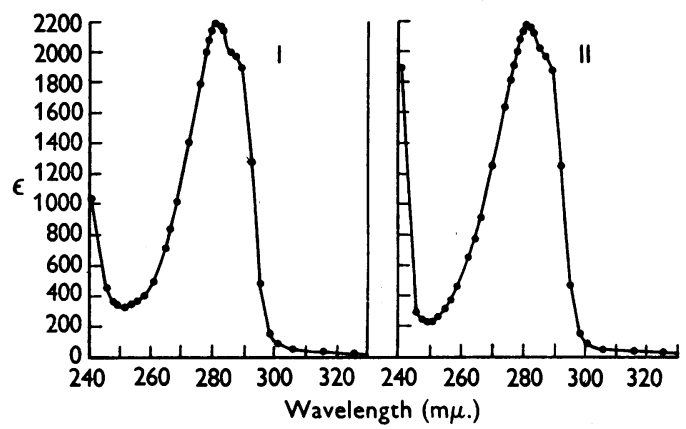

Fig. 3. Ultraviolet absorption spectra of oestriol and KC-4 in ethanol. I. Oestriol: $1.66 \times 10^{-4} \mathrm{M}$. II. KC-4: $1.74 \times 10^{-4} \mathrm{M}$. triacetate were markedly depressed by admixture with authentic oestriol and oestriol triacetate respectively. It seemed probable, therefore, that $\mathrm{KC}-4$ was an isomer of oestriol.

On carrying out Kober reactions on $\mathrm{KC}-4$ and authentic oestriol by the procedure of Brown (1952) as modified by Bauld (1954) it was found that while the colours given by the two compounds with a $20 \mathrm{~min}$. heating in the first stage of the reaction were qualitatively almost identical spectroscopically (Fig. 4), that given by $\mathrm{KC}-4$ was somewhat

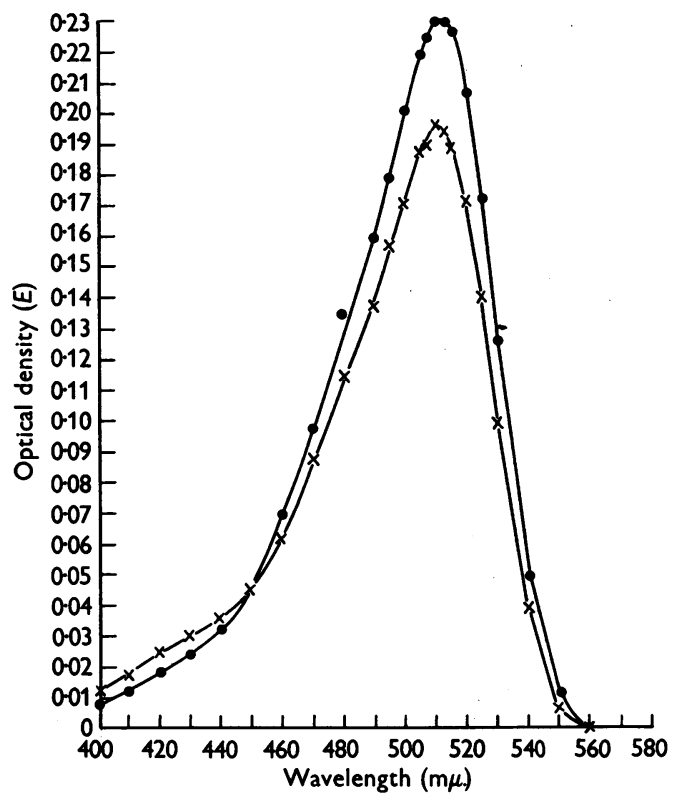

Fig. 4. Absorption spectra of colours developed by oestriol $(x)$ and KC-4 (O) in the Kober reaction with $20 \mathrm{~min}$. heating in first stage. KC-4, 5.01 $\mu \mathrm{g}$. in final vol. of $3.3 \mathrm{ml}$.; oestriol, $4.80 \mu \mathrm{g}$. in final vol. of $3.3 \mathrm{ml}$.

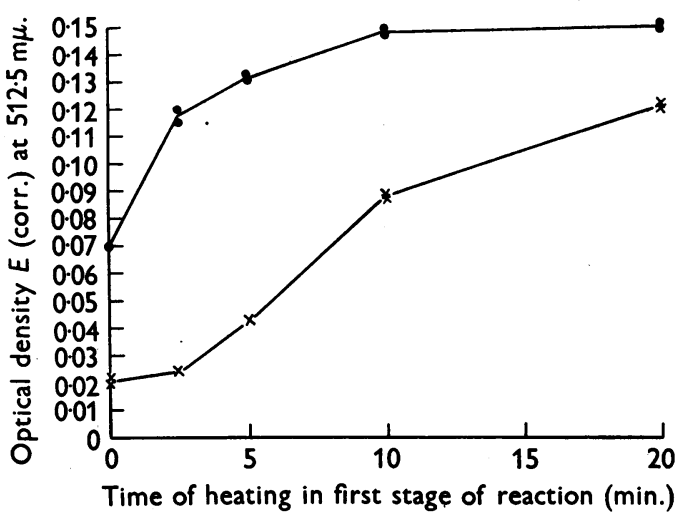

Fig. 5. Effect of variation in time of heating in the first stage of the Kober reaction on intensities of final colours developed by oestriol $(X)$ and KC-4 (O). Concentrations as in Fig. 4. 
more intense. Furthermore, when the time of heating in the first stage of the reaction was varied it was found that maximal colour was developed by KC-4 with a much shorter first-stage heating time than was required for oestriol (Fig. 5). In view of the possibility (cf. Bauld, 1953) that the first stage of the Kober reaction with oestriol may involve a dehydration to oestrone, it seemed reasonable to suppose that KC-4 might be a stereoisomer of oestriol which was more sensitive than the latter to the dehydrating action of sulphuric acid-i.e. one of the two stereoisomers with the cis configuration of the 16- and 17-hydroxyl groups. In this connexion it appeared significant that 16-epioestriol (Huffman, 1942 ; Huffman \& Darby, 1944; Huffman $\&$ Lott, 1947, 1949) was found by Marlow (1950) to give a more intense colour in the Kober reaction than oestriol itself. Subsequently, proof for the presence of a cis glycol grouping in KC-4 was obtained by the preparation of an acetonide, m.p. ca. $95^{\circ}$ and 183$185^{\circ}$.

A comparison of the optical rotation and meltingpoint data obtained for KC-4 and its derivatives with those reported by Huffman (1942), Huffman \& Darby (1944) and Huffman \& Lott (1947, 1949) for synthetic 16-epioestriol and its derivatives (see Table 1) suggested the possibility that the two compounds might be identical. An authentic specimen of 16-epioestriol, m.p. 278-281 ${ }^{\circ}$ (our determination), was very kindly supplied to us by Dr Huffman, and on admixture of this with KC.4 the melting point was not depressed. An acetate of the authentic 16-epioestriol was prepared (m.p. 152-154 ${ }^{\circ}$ ), and the mixed melting point with $\mathrm{KC}-4$ acetate showed no depression. There can be no doubt, therefore, that KC-4 and 16-epioestriol are identical.

\section{EXPERIMENTAL}

\section{Methods}

Analytical partition chromatograms. The procedure of Bauld (1953) was followed using $1 \times 10 \mathrm{~cm}$. columns with a stationary phase of $5 \mathrm{ml} .70 \%(\mathrm{v} / \mathrm{v})$ methanol on $5 \mathrm{~g}$. Celite 535, and ethylene dichloride as the mobile phase. The chromatograms were run at a temperature of $18^{\circ}$ at a percolation rate of $10 \mathrm{ml} . / \mathrm{hr}$. The Celite, methanol and ethylene dichloride were purified by the methods described by Bauld (1953).
In all cases $30 \mathrm{ml}$. of eluate were collected. In some cases Kober reactions were carried out on the residues obtained by evaporation of successive $2.0 \mathrm{ml}$. portions of the whole eluate, while in others $2.0 \mathrm{ml}$. portions were collected only for the first 18 or $20 \mathrm{ml}$., the remainder being pooled.

Kober reactions were carried out by the method of Brown (1952) as modified by Bauld (1954).

Melting points. All melting points given are uncorrected for emergent stem. Those for oestriol and 16-epioestriol were determined with a conventional type apparatus in sealed evacuated capillary tubes. In this way the decomposition undergone by these compounds when heated in air to just below their melting points was entirely avoided. All other melting points were determined on a microscope hotstage.

Miscellaneous. The ' $\mathrm{pH} \mathrm{10.5}$ buffer' used for washing ether extracts of the acid-hydrolysed urine was prepared by making up $52 \mathrm{ml}$. of $5 \mathrm{~N}-\mathrm{NaOH}$ to $400 \mathrm{ml}$. with $8.5 \%(\mathrm{w} / \mathrm{v})$ $\mathrm{NaHCO}_{3}$.

The 'pH 12.0 buffer' used for the countercurrent separation was prepared by mixing $250 \mathrm{ml} .0 \cdot 1 \mathrm{M}-\mathrm{Na}_{2} \mathrm{HPO}_{4}$ with $216 \mathrm{ml} .0 \cdot 1 \mathrm{~N}-\mathrm{NaOH}$ and making up to $500 \mathrm{ml}$. with water.

Ultraviolet absorption spectra were determined with a Unicam ultraviolet spectrophotometer SP 500.

All samples for $\mathrm{C}$ and $\mathrm{H}$ analysis were dried for $4 \mathrm{hr}$. at $80^{\circ}$ in vacuo over $\mathrm{P}_{8} \mathrm{O}_{5}$.

\section{Isolation of oestriol and $K C-4$ from the urine of pregnant women}

Separation of crude crystalline oestriol. Late pregnancy urine (210 l.) was collected without preservative and boiled for $1 \mathrm{hr}$. with $15 \mathrm{vol}$. $\%$ of $10 \mathrm{~N}-\mathrm{HCl}$. After saturation with $\mathrm{NaCl}$ the mixture was extracted thoroughly with ether, and the extract washed with ' $\mathrm{pH} 10.5$ buffer' to remove acidic substances. Further removal of unwanted impurities was effected by shaking the ether vigorously with a small volume of $2 \mathrm{~N}-\mathrm{NaOH}$, adding an excess of $8.5 \% \mathrm{NaHCO}_{3}$, running off the aqueous layer, and finally washing with water. The washed ether solution was extracted with $0 \cdot 1 \mathrm{~N}$ $\mathrm{NaOH}$, and the 'strong phenolic' fraction recovered from the extract by ether extraction after acidification with $\mathrm{H}_{2} \mathrm{SO}_{4}$, the ether extract being washed with ' $\mathrm{pH} 10.5$ buffer' and with water before being evaporated to dryness.

To the product $(8 \cdot 38 \mathrm{~g}$.) were added $25 \mathrm{ml}$. ethyl acetate. After standing overnight at $0^{\circ}$, the crude crystalline material was filtered off, washed with cold ethyl acetate and dried in vacuo.

Isolation of authentic oestriol. The crude crystalline oestriol thus obtained $(1.36 \mathrm{~g}$.) was dissolved in the minimum volume of boiling methanol $(45 \mathrm{ml}$.) and allowed to stand at room temperature overnight. The crystals deposited were filtered off, washed with cold methanol, and the mother

Table 1. Comparison of properties of KC-4 and its derivatives with those of 16-epioestriol as reported by Huffman (1942), Huffman \& Darby (1944) and Huffman \& Lott (1947, 1949)

$\begin{array}{llcc} & & \text { KC-4 } & 16-\text { epioestriol } \\ \text { Triol } & \text { M.p. }\left({ }^{\circ}\right) & 277-280 & 274-276 \\ & {[\alpha]_{\text {D }} \text { in ethanol }} & +85^{\circ *} & +88^{\circ} \dagger \\ \text { Triacetate } & \text { M.p. }\left({ }^{\circ}\right) & 151-152 & 152 \\ \text { Acetonide } & \text { M.p. }\left({ }^{\circ}\right) & c a .95 \text { and } & 103 \cdot 5-104 \cdot 5 \text { and } \\ & & 183-185 & 183 \cdot 5-184 \cdot 5 \\ & * \text { At } 19^{\circ} . & \dagger \text { At } 29 \cdot 5^{\circ} .\end{array}$


liquor and washing were set on one side for the isolation of KC-4. After two further recrystallizations from methanol $120 \mathrm{mg}$. of oestriol m.p. $273 \cdot 5-275^{\circ},[\alpha]_{\mathrm{D}}^{19}+61^{\circ}(0 \cdot 296 \%$ in ethanol), $\epsilon_{281}, 2181$, were obtained.

Countercurrent separation of $K C-4$ fraction. Evaporation of the methanolic mother liquor and washing of the first crystallization of the authentic oestriol yielded $0.975 \mathrm{~g}$. of solid material which was divided into two equal parts for the countercurrent separation. Each part was separately fractionated by an 8-transfer procedure in nine separating funnels using in each funnel 1 l. 'pH 12.0 buffer' and 11 . ether, the phases having been previously equilibrated with one another. After the completion of the distribution the contents of each funnel were acidified with $\mathrm{H}_{2} \mathrm{SO}_{4}$, shaken and the aqueous layer was run off. The ether solutions were washed with ' $\mathrm{pH} 10.5$ buffer', 8.5\% $\mathrm{NaHCO}_{3}$ and water, and evaporated to dryness. The fractions thus obtained from 'plates' 2-4 (funnels 3-5) were combined for further purification of the KC-4.

Purification of KC.4 fractions by column partition chromatograms. Each of the two KC-4 fractions obtained as described above, after solution in $15 \mathrm{ml}$. ethylene dichloride, was chromatographed on a column with $80 \mathrm{ml} .70 \%(\mathrm{v} / \mathrm{v})$ methanol on $80 \mathrm{~g}$. Celite as stationary phase and ethylene dichloride as mobile phase. Twenty successive $40 \mathrm{ml}$. volumes of eluate were collected, evaporated to dryness, and Kober reactions carried out on appropriate small fractions of each (see Fig. 2). It was evident from the elution patterns that the KC-4 was concentrated in cuts 4-7 from each chromatogram. The material in these cuts from both columns was combined yielding $39 \mathrm{mg}$. of a nearly white solid.

Isolation of $K C$-4. The chromatographically purified material was washed with a small volume of benzene at room temperature, and in this way freed from a small amount of colourless gummy material which was discarded. After rapid washing with a small volume of well-chilled methanol, the benzene-insoluble material was crystallized once from aqueous methanol and once from methanolbenzene, yielding $10.3 \mathrm{mg}$. of white crystals, m.p. 277-280', $[\alpha]_{\mathrm{D}}^{19},+85^{\circ}$ in ethanol $(c, 0 \cdot 286), \epsilon_{281}, 2165$. (Found: $\mathrm{C}, 75 \cdot 1$; $\mathrm{H}, 8 \cdot 4$. Calc. for $\mathrm{C}_{18} \mathrm{H}_{24} \mathrm{O}_{3}: \mathrm{C}, 75 \cdot 0 ; \mathrm{H}, 8.4 \%$.) Mixed with authentic oestriol, the m.p. was $257-270^{\circ}$; with authentic 16-epioestriol, the m.p. was $278-281^{\circ}$.

A further $8.0 \mathrm{mg}$. KC-4, m.p. $275-277^{\circ}$ were recovered from the material in the cold methanol washings and mother liquors of the analytical sample by two crystallizations from methanol-benzene.

\section{Characterization of $\mathrm{KC} \cdot \mathbf{4}$}

Kober reaction on $\mathrm{KC}-4$ and oestriol: variation in time of heating in first stage of reaction. Solutions of $\mathrm{KC}-4$ and authentic oestriol were prepared by dissolving $0.480 \mathrm{mg}$. and $0.501 \mathrm{mg}$. of the two compounds respectively in $10 \mathrm{ml}$. volumes of ethanol. Into two series of ten test tubes $0.1 \mathrm{ml}$. of the KC-4 and oestriol solutions respectively were pipetted and evaporated to dryness under an air stream in a boilingwater bath after the addition to each of $50 \mathrm{mg}$. solid quinol. Pairs of tubes from each series were then treated as follows: after the addition of $\mathbf{2 . 6} \mathrm{ml}$. of the oestriol Kober reagent (Brown, 1952; Bauld, 1954) to each tube, the pairs were then heated in a boiling-water bath for $x$ min. (where $x=0$, $2 \cdot 5,5,10$ and 20 for successive pairs from each series). After cooling in cold water for exactly $5 \mathrm{~min} ., 50 \mathrm{mg}$. solid quinol and $0.7 \mathrm{ml}$. water were added to each tube and they were then reheated in the boiling-water bath for $15 \mathrm{~min}$. After cooling in cold water for $5 \mathrm{~min}$. the optical densities were measured in a Unicam spectrophotometer SP 600 at 480 , 512.5 and $545 \mathrm{~m} \mu$., and the corrected density at $512.5 \mathrm{~m} \mu$. was obtained by applying the Allen (1950) formula. The curves showing the relationship between optical density at $512.5 \mathrm{~m} \mu$. (corrected) and time of heating in the first stage of the reaction are shown in Fig. 5. Absorption spectra over the range $400-560 \mathrm{~m} \mu$. for the colours developed by both compounds with a $20 \mathrm{~min}$. heating period in the first stage were also determined (Fig. 4).

$K C-4$ triacetate. The $\mathrm{KC}-4$ recovered from the mother liquors together with that recovered from the determination of the optical rotation (in all $11.3 \mathrm{mg}$.) was treated at room temperature for $24 \mathrm{hr}$. with $0.5 \mathrm{ml}$. anhydrous pyridine and $0.5 \mathrm{ml}$. acetic anhydride. After the addition of ice and water the crude acetate was filtered off, washed thoroughly with water and dried. After two crystallizations from hexane, crystals, m.p. 151-152 ${ }^{\circ}$ were obtained. (Found: C, 69.7; $\mathrm{H}, 7 \cdot 0$. Calc. for $\mathrm{C}_{24} \mathrm{H}_{30} \mathrm{O}_{6}: \mathrm{C}, 69 \cdot 5 ; \mathrm{H}, 7 \cdot 3 \%$.) Mixed with authentic oestriol triacetate (m.p. 126-128 ${ }^{\circ}$ the m.p. was $107-116^{\circ}$; with authentic 16-epioestriol triacetate (m.p. $152-154^{\circ}$ ) it was $150-153^{\circ}$.

$K C-4$ acetonide. To the remainder of the analytical sample of KC-4 (2.2 mg.) was added $1.0 \mathrm{ml}$. of anhydrous acetone containing $1 \%(\mathrm{w} / \mathrm{v})$ of $\mathrm{HCl}$ (concentration determined by titration after dilution with water). After shaking for a few minutes to dissolve the KC-4, the solution was allowed to stand at room temperature for $30 \mathrm{~min}$. and then diluted with about 10 vol. of ice and water. The insoluble material which separated was filtered off, washed thoroughly with water, dried in vacuo over $\mathrm{CaCl}_{2}$ and $\mathrm{KOH}$, and finally crystallized from aqueous methanol. The product melted at about $95^{\circ}$ (not sharp), resolidified over the range $124-135^{\circ}$ on further heating, and remelted at $183-185^{\circ}$ (cf. Huffman \& Lott, 1947, 1949).

\section{DISCUSSION}

The isolation of 16-epioestriol (oestra-1:3:5-triene$3: 16 \beta: 17 \beta$-triol) from the acid-hydrolysed urine of pregnant women which is described in this paper would appear to be the first recorded isolation of this substance from a natural source. While it is tempting to speculate that the occurrence together of oestriol and 16-epioestriol in urine might point to 16-oxo-oestradiol-17 $\beta$ (3:17 $\beta$-dihydroxyoestra-1:3:5trien-16-one) as the common metabolic precursor of both substances, it should be pointed out that the possibility that 16-epioestriol may be an artifact has not been excluded.

It appears probable that the fourth Koberchromogen detected by one of us in extracts of the urine of a non-pregnant woman was also 16-epioestriol, since its chromatographic behaviour in the system $70 \%$ methanol-ethylene dichloride was similar to that of the latter substance in the same system. It is also possible that the fourth Koberchromogen detected by Brown (personal communication) in methylated phenolic fractions from pregnancy urine was 16-epioestriol 3-methyl ether; but until the behaviour of the latter on alumina 
columns has been examined this possibility must remain in doubt. The further possibilities that one of the new urinary fluorogens detected by Migeon (1953) and the fluorogenic impurity in crystalline oestriol detected by Braunsberg et al. (1954) may be identical with 16-epioestriol obviously require investigation.

\section{SUMMARY}

A new Kober-chromogen has been isolated from acid-hydrolysed human pregnancy urine in a yield of about $0.1 \mathrm{mg}$./1. It has been shown to be identical with 16-epioestriol (oestra-1:3:5-triene-3:16 $\beta: 17 \beta$ triol).

We gratefully acknowledge a grant from the Medical Research Council from which the cost of this work was defrayed, the generosity of Dr M. N. Huffman of the Oklahoma Medical Research Foundation in sending us a specimen of authentic 16-epioestriol, the skill of $\mathrm{Dr} J . \mathrm{W}$. Minnis who carried out the microanalyses, the technical assistance of Miss Winifred Martin and Mr J. Knowles, and the help of Professor R. J. Kellar and Dr T. N. MacGregor of the Department of Obstetrics and Gynaecology, who arranged for the collection of urine.

\section{REFERENCES}

Allen, W. M. (1950). J. clin. Endocrin. 10, 71.

Bauld, W.S. (1953). Ph.D. Thesis, University of Edinburgh. Bauld, W. S. (1954). Biochem. J. 56, 426.

Braunsberg, H., Stern, M. I. \& Swyer, G. I. M. (1954). J. Endocrin. 11, 189.

Brown, J. B. (1952). J. Endocrin. 8, 196.

Cohen, S. L. \& Marrian, G. F. (1934). Biochem. J. 28, 1603.

Engel, L. L. (1950). Recent Progr. Hormone Res. 5, 335.

Huffman, M. N. (1942). J. Amer. Chem. Soc. 64, 2235.

Huffman, M. N. \& Darby, H. H. (1944). J. Amer. Chem. Soc. 66, 150.

Huffman, M. N. \& Lott, M. H. (1947). J. Amer. Chem. Soc. $69,1835$.

Huffman, M. N. \& Lott, M. H. (1949). J. Amer. Chem. Soc. 71, 719.

Marlow, H. W. (1950). J. biol. Chem. 183, 167.

Marrian, G. F. (1930). Biochem. J. 24, 1021.

Migeon, C. J. (1953). J. clin. Endocrin. Metab. 13, 674.

Zondek, B. \& Finkelstein, M. (1952). Endocrinology, 50, 271.

\title{
The Content and Distribution of Cytochrome $c$ in the Fatty Liver of Rats
}

\author{
By M. U. DIANZANI AND. I. VITI \\ Institute of General Pathology, University of Genoa, Genoa, Italy
}

(Received 26 July 1954)

Many authors have been interested in the study of the metabolic changes occurring in the liver during experimental fatty degeneration. Though the fundamental metabolic deviation is not yet clear, some phenomena have been described. One of these is the increase of oxygen uptake by liver slices, which was reported by several investigators (Meier \& Thoenes, 1933; Califano, 1934; Ennor, 1942; Biagini, 1951). This increase has been recently attributed to a change which takes place in the mitochondria during the fatty degeneration (Dianzani, 1953) and is characterized by an increase of oxidations and by uncoupling of oxidations from phosphorylations. Prader (1947) reported a threefold increase of the cytochrome $c$ content of the rabbit liver which has undergone fatty degeneration as a result of phosphorus poisoning. He used for the determination of cytochrome $c$ the method of Prader \& Gonella (1947) and attributed the high oxygen uptake of the fatty liver to an increased rate of metabolism. The values for the cytochrome $c$ content of normal liver reported by Prader were, however, lower than those obtained by other authors who employed different methods (Rosenthal \& Drabkin, 1943; Stotz, 1939; Potter \& Dubois, 1942).
The aim of the present study was to determine the content and the distribution of cytochrome $c$ in cellular fractions of the liver by two independent methods.

\section{EXPERIMENTAL}

Material and methods. Adult albino rats weight 170 $180 \mathrm{~g}$. and rabbits weighing $1 \cdot 5-1 \cdot 8 \mathrm{~kg}$. were used. They were fed $a d l i b$. with a standard diet containing all vitamins and dietary factors. Fatty degeneration of the liver was produced in rats by daily subcutaneous injections of either $0.2 \mathrm{ml}$. of a $20 \%(\mathrm{v} / \mathrm{v})$ soln. of $\mathrm{CCl}_{4}$ in olive oil, or of $0.1 \mathrm{ml}$. of a $0.5 \%$ soln. of white phosphorus in olive oil. Phosphorus was administered for 1-4 days, $\mathrm{CCl}_{4}$ for 1-60 days. Fatty degeneration in rabbits was produced by injecting $0.5 \mathrm{ml}$. $0.5 \%$ soln. of phosphorus in olive oil for 2-6 days. The animals were killed by bleeding $24 \mathrm{hr}$. after the last injection; they were kept fasting for $20 \mathrm{hr}$. before killing in order to reduce (i) the amount of glycogen, which can interfere with the fractionation procedure (Claude, 1946) and the determination of cytochrome $c$ (Prader \& Gonella, 1947), and (ii) the amount of protein in the mitochondria (Muntwyler, Seifter \& Harkness, 1950).

Immediately after the death of the animals, the livers were dissected, weighed, transferred to the cold room at $2^{\circ}$, and $10 \%$ homogenates were prepared in a Potter-Elvehjem glass homogenizer with $0.25 \mathrm{~m}$ sucrose. Separation of cellular fractions was carried out in the cold room by the procedure 